\title{
4D MR imaging of cerebrospinal fluid flow in Chiari I malformation with and without syringomyelia and flow changes after decompressive surgery
}

\author{
Jan Robert Kröger ${ }^{1 *}$, Alena Juettner ${ }^{1}$, Angela Brentrup ${ }^{2}$, Barbara Fiedler ${ }^{3}$, Gerard Crelier $^{4}$, Wolfram Schwindt ${ }^{1}$, \\ Thomas Niederstadt ${ }^{1}$, Walter Heindel ${ }^{1}$, David Maintz ${ }^{1}$, Alexander C Bunck ${ }^{1}$
}

From 15th Annual SCMR Scientific Sessions

Orlando, FL, USA. 2-5 February 2012

\section{Background}

The aim of our study was to evaluate the feasibility of $4 \mathrm{D}$ phase contrast (PC) flow imaging for visualisation and analysis of cerebrospinal fluid (CSF) flow in Chiari I malformation. CSF flow was compared between healthy volunteers and patients with Chiari I malformation with and without syringomyelia. Moreover, the effect of a craniocervical decompression on CSF flow was studied in Chiari I patients with syringomyelia.

\section{Methods}

20 patients with Chiari I malformation and 10 healthy volunteers were examined using 4D PC flow imaging. 11 patients had syringomyelia and 1 patient presented with a presyrinx. Of these, 9 patients underwent craniocervical decompression and flow data was assessed pre- and postoperatively. Flow images were analyzed by 2 blinded readers. Quantitative flow parameters including peak flow velocities, maximum flow volume and timing of systole were assessed at the craniocervical junction and the cervical spinal canal.

\section{Results}

Qualitative analysis showed superior interreader agreement for 4D PC flow images compared to single-slice $2 \mathrm{D}$ axial $(\mathrm{C} 1)$ and sagittal (mid-plane) images $(\kappa=0.67$ vs. $\kappa=0.57$ vs. $\kappa=0.02$ ). Flow alterations were found in 17 patients consisting of anterolateral flow jet $(n=14)$

'Department of Clinical Radiology, University Hospital of Muenster, Muenster, Germany

Full list of author information is available at the end of the article or flow vortex $(\mathrm{n}=5)$ formation and flow inhomogeneity $(n=3)$. In patients peak velocities at the craniocervical junction were found to be increased $(-15.5 \pm 11.3 \mathrm{~cm} /$ sec vs. $-4.7 \pm 0.7$ in healthy volunteers, $\mathrm{p}<0.001)$ with maximal velocities of up to $37.9 \mathrm{~cm} / \mathrm{sec}$. Of the 9 patients who underwent craniocervical decompression 4 showed a decrease in syrinx size postoperatively. Postoperatively, maximum flow volumes increased significantly at $\mathrm{C} 2$ and the lower levels of the cervical spine. In the group with regredient syrinx size peak flow velocities decreased $(-19.4 \pm 14.4$ vs. $-10.5 \pm 3.8 \mathrm{p}=0.07)$ while patients without change in syrinx size showed increased peak flow velocities postoperatively $(-19.4 \pm$ 14.4 vs. $-25.7 \pm 17.3 \mathrm{p}=0.08$ ).

\section{Conclusions}

Analysis of cerebrospinal fluid dynamics using 4D PC flow imaging is superior to a $2 \mathrm{D}$ single slice approach. It allows for a comprehensive characterization of complex flow phenomena, which might be missed by $2 \mathrm{D}$ imaging. CSF flow is considerably altered in patients with Chiari I malformation. Analysis of CSF flow pre- and postoperatively suggests a correlation between reduction in peak flow velocity and change in syrinx size.

\section{Author details \\ 'Department of Clinical Radiology, University Hospital of Muenster, Muenster, Germany. ${ }^{2}$ Department of Neurosurgery, University Hospital of Muenster, Muenster, Germany. ${ }^{3}$ Department of General Pediatrics, Subdivision Pediatric Neurology, University Hospital of Muenster, Muenster, Germany. ${ }^{4}$ Institute for Biomedical Engineering, ETH and University of Zurich, Zurich, Switzerland.}

Published: 1 February 2012 
doi:10.1186/1532-429X-14-S1-W1

Cite this article as: Kröger et al:: 4D MR imaging of cerebrospinal fluid flow in Chiari I malformation with and without syringomyelia and flow changes after decompressive surgery. Journal of Cardiovascular Magnetic Resonance 2012 14(Suppl 1):W1.

Submit your next manuscript to BioMed Central and take full advantage of:

- Convenient online submission

- Thorough peer review

- No space constraints or color figure charges

- Immediate publication on acceptance

- Inclusion in PubMed, CAS, Scopus and Google Scholar

- Research which is freely available for redistribution

Submit your manuscript at www.biomedcentral.com/submit
C Biomed Central 